\title{
CFD Based Heat Transfer analysis of various Wavy Fin-and-Tube Heat Exchanger
}

\author{
Vikram Chavan* and R. R.Arakerimath \\ Department of Mechanical Engineering, Pune University, G. H. Raisoni College of Engineering \& Management, Wagholi, Pune , India \\ Accepted 15 June 2016, Available online 20 June 2016, Special Issue-5 (June 2016)
}

\begin{abstract}
The performance of fine-and-tube heat exchanger is enhanced by modifying fin shape to Wavy fin, fin angle and also material. The conventional resistance on air side is maximum up to 85\% of total resistance. This resistance should be minimizing to enhance the heat transfer rate. Wavy fins are particularly attractive for their simplicity of manufacture and potential for enhanced thermal -hydraulic performance. Here performance of wavy-fin and tube heat exchanger is calculated for different temperature and wave angle. CFD analysis is taken for Wavy angle- $0^{\circ}, 10^{\circ}$, 17.44․ we get the maximum heat flux is $12227 \mathrm{w} / \mathrm{m}^{2}$ for fin angle 17.44 and water inlet temperature $70^{\circ} \mathrm{C}$. Heat flux increases with fin angle and also pressure loss increases. Maximum pressure loss is 1.80 Pascal for $17.44^{\circ}$ fin angle , water inlet temperature $70^{\circ} \mathrm{C}$ and air flow velocity $3 \mathrm{~m} / \mathrm{s}$. Here air inlet temperature $\left(30^{\circ} \mathrm{C}\right)$ is constant for all the model also water mass flow rate is constant (2.5 lit/hr.)
\end{abstract}

Keywords: Wavy fin; Wavy fin-and-tube heat exchanger; Wavy fin angle, CFD analysis;

\section{Introduction}

Finned surfaces are widely used in heat exchanger to enhance the heat transfer and reduce the size. Common among these are radiators, charge air coolers, airconditioning evaporators and condensers to meet the demand for saving energy and resources. The heat transfer is normally limited by the thermal resistance on the air side of the heat exchangers. so, various augmented surfaces have been developed to improve air side heat transfer performance. Typical fin geometries are plain fin, wavy fin, offset strip fin, perforated fin and multi-louvered fin, which, besides increasing the surface area of the exchanger, also improve the convection heat transfer coefficients. Of these, wavy fins are simple for manufacture and potentials for enhanced thermal-hydraulic performance. The air side thermal hydraulic performance of wavy fin and circular tube heat exchangers have been studied by many researchers

A lot of experimental and numerical studies conducted on airside heat transfer performances of wavy fin and circular tube heat exchangers. Wang et al. experiments on the heat transfer and pressure drop characteristics of wavy fin and tube heat exchangers. Wongwises and Chokeman investigated the effects of fin pitch and number of tube rows on the air side performance of herringbone wavy fin and tube heat exchangers. Jang and Chen studied the heat transfer

*Corresponding author: Vikram Chavan and fluid flow in a three-dimensional wavy fin-andtube heat exchanger. Manglik et al. studied the effects of fin density on low Reynolds number forced convection in three-dimensional wavy-plate-fin compact channels by numerical simulation.

Jones and Russell , Saboya and Sparrow, Rosman et al. and Ay et al. conclude that there exists a great variation of the heat transfer rate on the fin surface of the plate fin-and-tube heat exchanger. This also implies that the heat transfer coefficient on the fin surface is very nonuniform and the actual steady-state heat transfer coefficient on the fin surface should be the function of position. But it is very difficult to measure the local heat transfer coefficient on the fins, because for this purpose the local fin temperature and local heat flux are needed. The study of the distributions of the local heat transfer coefficient and fin efficiency on the fin surface is an important task to design highperformance heat exchangers because the results used to point out the areas where the enhancement is mostly needed and effective. Mao Yu Wen and Ching Yen Ho provide the information of an experimental design on the elements of the fin and tube heat exchanger. In this study the three different types of the fin design were proposed (plate fin, wavy fin, and compounded fin) and experiment conducted. The heat transfer coefficient, the pressure drop of the air side, the Colburn factor, and fanning friction factor against air velocity (1-3 m/s) and Reynolds number (6002000) have been discussed in this paper. 
Here in this study, the performance of fin and tube heat exchanger is enhanced by wavy fin augmentation technique.

\section{Experimental}

\subsection{Experimental set-up}

The schematic diagram of the wind tunnel used in the study is shown in the fig. 1 . Air and hot water were used as working fluids. The system contains the heat exchangers, water flow loop, air supply, measurement and data acquisition system, the wind tunnel system was designed to suck room air over the finned side of the heat exchangers by a $15000 \mathrm{~W}$ centrifugal fan. The speed of the fan could be adjusted by a frequency inverter. The tunnel is a rectangular duct $270 \times 220$ $\mathrm{mm}$ in cross-section. To minimize heat loss to the surroundings, the tunnel surface is insulated with a 1 $\mathrm{cm}$ thick glass wool layer. Being supported by stands of perforated steel plate, the tunnel system is kept 750 $\mathrm{mm}$ above the floor level of the laboratory. The inlet and exit temperature across the air side of the heat exchangers are measured by two T-type thermocouple. The inlet measuring mesh consists of eight thermocouples while the exit contains sixteen thermocouples. These thermocouples were precalibrated which have an accuracy of $0.10 \mathrm{C}$. The measuring points are located at positions as described in the ASHRAE standard. These data signals are individually measured and then averaged. The air pressure drop across the heat exchangers and the nozzles were, respectively, measured by precise differential pressure transducers, whose accuracies were $0.4 \%$ and $0.25 \%$. The models of the two differential pressure transducers are WIDERPLUS-DP and C268. The air flow measuring station was a multiple nozzle code tester based on the ISO 5167 standard. The hot water loop consist of a storage tank, a $100 \mathrm{~kW}$ electric heater, a centrifugal pump, a flow meterand a control unit. The purpose of this loop was to transfer heat to the air flowing through the heat exchangers. The temperature of the hot water in the water tank was measured by pre-calibrated RTDs (Pt$100 \mathrm{X}$ ) and was controlled by the temperature controller. Its accuracy was within $0.10 \mathrm{C}$. After heating the water to the required temperature, the hot water was pumped out of the storage tank, delivered to the heat exchanger and then returned to the storage tank. The water temperatures at the inlet and outlet of the heat exchanger were measured by two per-calibrated RTDs (Pt-100 X) which have an accuracy of 0.1 0C.4

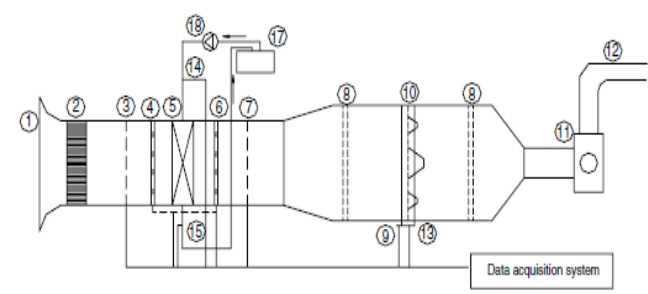

Fig.1 Schematic diagram of the wind tunnel test apparatus
1, Air inlet

2, Honey cone Straightener

3 , T/C inlet temperature measuring station

4, Pressure tap (inlet)

5, Test unit

6, Pressure tap (outlet)

7, Outlet temperature measuring station

8 , setting means

9 , Static pressure taps

10 , multiple nozzle plate

11 , Variable exhaust fan system

12 , air outlet

13,Difference pressure tap nozzle

14 , inlet temperature tap water

15 , outlet temperature tap water

16 , data acquisition system

17 , hot water tank

18, Water pump

\subsection{Test Heat Exchanger}

The schematic diagram of the wavy fin-and-tube heat exchanger is shown in Fig. 2 which has three row round tubes in staggered arrangement. The tube outside diameter Dc is $10.55 \mathrm{~mm}$, fin pitch is $10 \mathrm{~mm}$, fin thickness $0.7 \mathrm{~mm}$. Wavy angle vary - $0^{0}, 10^{0}, 15^{0}$ ,17.440. Air flow direction length is $43.3 \mathrm{~mm}$ and wave amplitude is $1.5 \mathrm{~mm}$. transverse pitch is $25 \mathrm{~mm}$ and longitudinal pitch is $21.7 \mathrm{~mm}$. Material selection is most important parameter for fin and tube heat exchanger. Copper tube and copper fin are commonly used in fin and tube type heat exchanger. Copper tube and fin are generally manufactured from any of five alloys - C10200, C10300, and C12000. This is the purest forms of copper which contain 99.9\% (min.) copper and $0.04 \%$ phosphorus. Generally fins are made from aluminum.
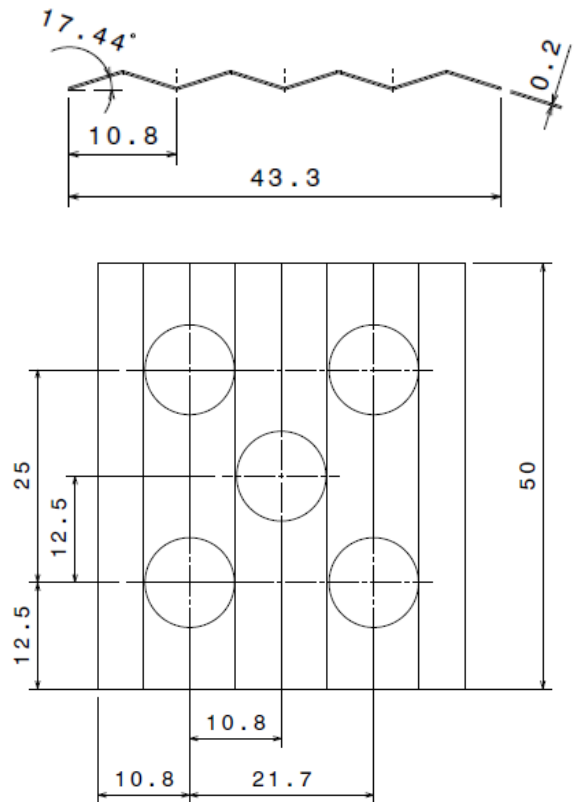

Fig.2 Wavy fin and tube exchangers 


\section{CFD Analysis}

\subsection{Steps in analysis}

1) Modeling: - Modeling is done in CATIA software 2) Import: -CATIA model import in ANSIS workbench 3) Meshing:- Triangular Surface mesher is used for meshing, span angle center is fine , Curvature normal angle is $18^{0}$. Below figure shows the models with meshing.

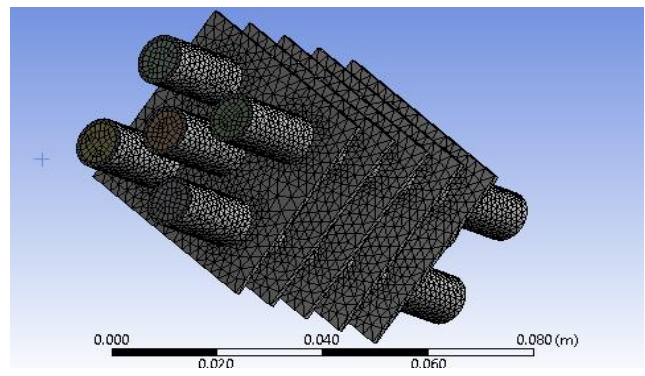

Fig.3 Meshing-Fins with wavy angle $0^{0}$

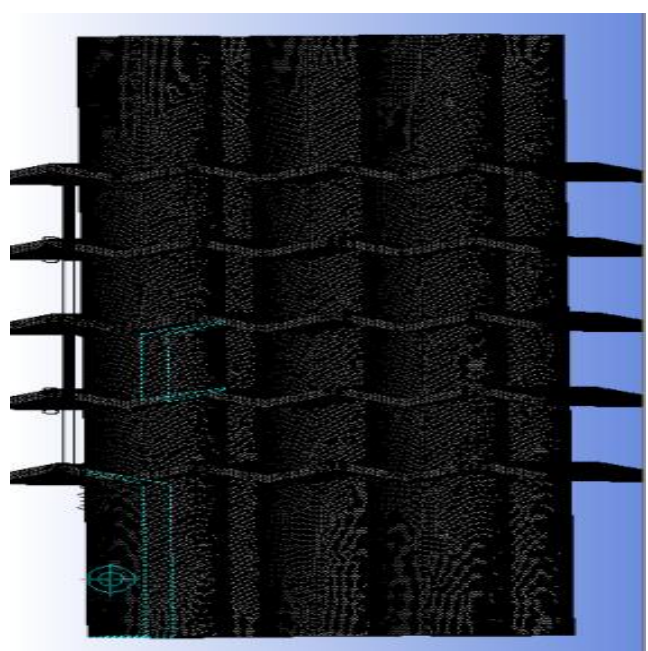

Fig.4 Meshing- fins with wavy angle -100, 17.440

4) Boundary Conditions: - Air temperature $30^{\circ} \mathrm{c}$, air flow velocity $2 \mathrm{~m} / \mathrm{s}$ and $3 \mathrm{~m} / \mathrm{s}$ water flowing through tubes temperature of water is $60^{\circ} \mathrm{C}$ and $70^{\circ} \mathrm{c}$ and mass flow rate is $2.5 \mathrm{lit} / \mathrm{hr}$.

5) Solution setup: - In solution setup we choose energy on and viscous models as standard k-e and non-eq wall fn.

5) Solver - CFD fluent

6) Calculation of model

7) Result plots

\section{Results}

The CFD analysis results are carried out for temperature distribution, pressure distribution and heat flux as shown in following figures. Water flow rate is constant $2.5 \mathrm{lit} / \mathrm{hr}$ and air inlet temperature is constant $30^{\circ} \mathrm{c}$

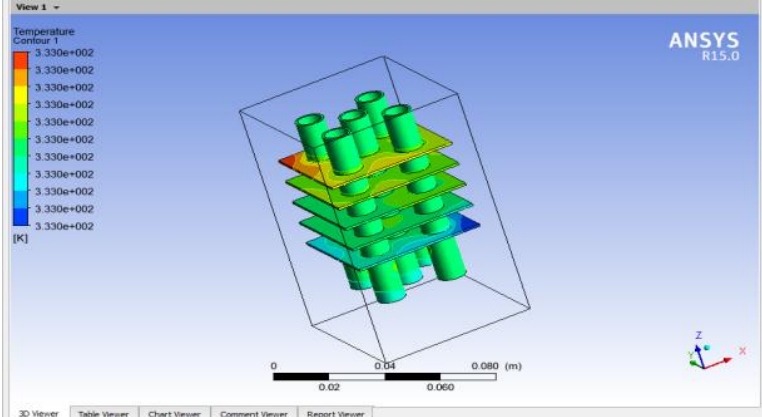

Fig.5 Temperature distribution for $0^{0}$ wavy angle $60^{0}$ inlet water temperature and $2 \mathrm{~m} / \mathrm{s}$ air flow rate

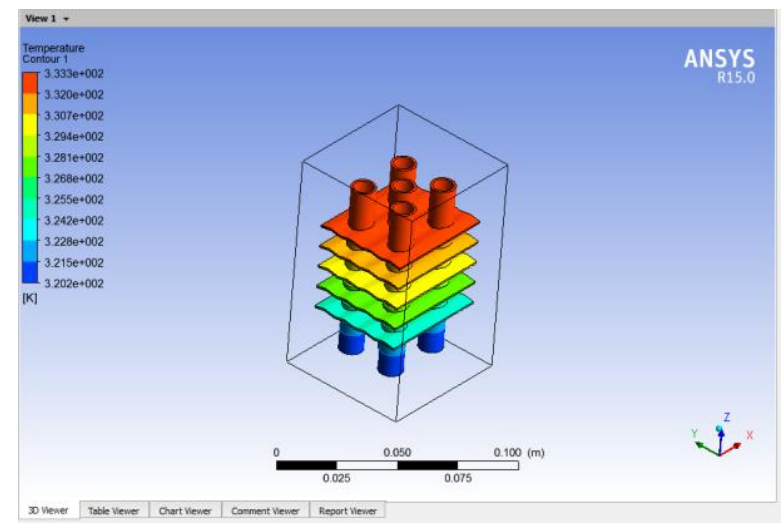

Fig.6 Temperature distribution for $10^{0}$ wavy angle, $60^{\circ}$ inlet water temperature and $2 \mathrm{~m} / \mathrm{s}$ air flow rate

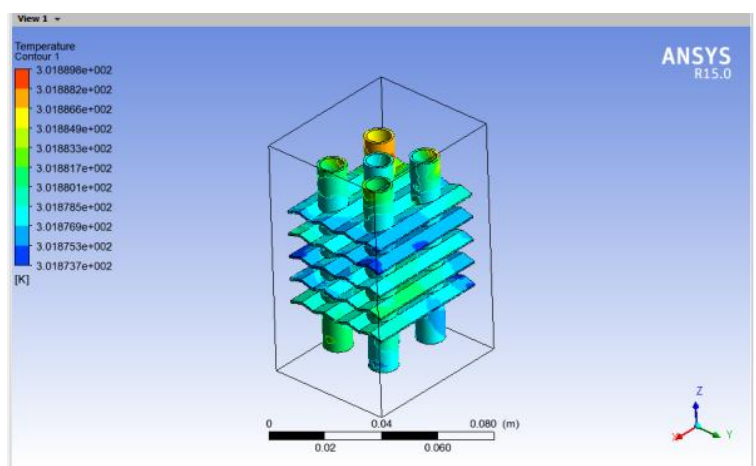

Fig.7 Temperature distribution for $17.44^{\circ}$ wavy angle, $60^{\circ}$ inlet water temperature and $2 \mathrm{~m} / \mathrm{s}$ air flow rate

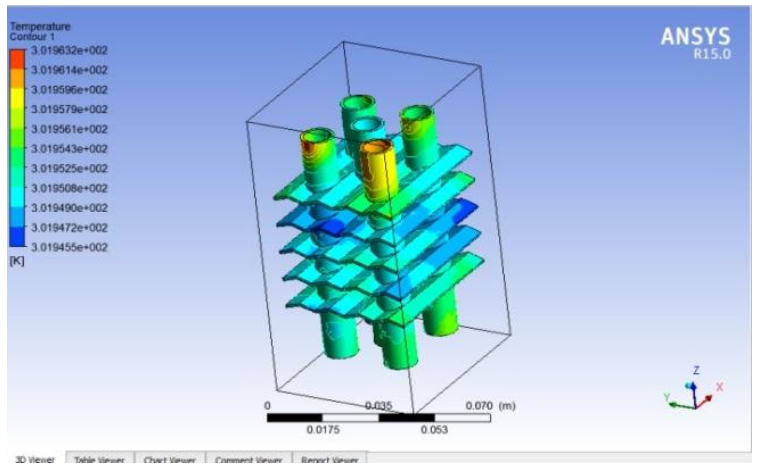

Fig.8 Temperature distribution for $17.44^{0}$ wavy angle, $60^{\circ}$ inlet water temperature and $3 \mathrm{~m} / \mathrm{s}$ air flow rate 


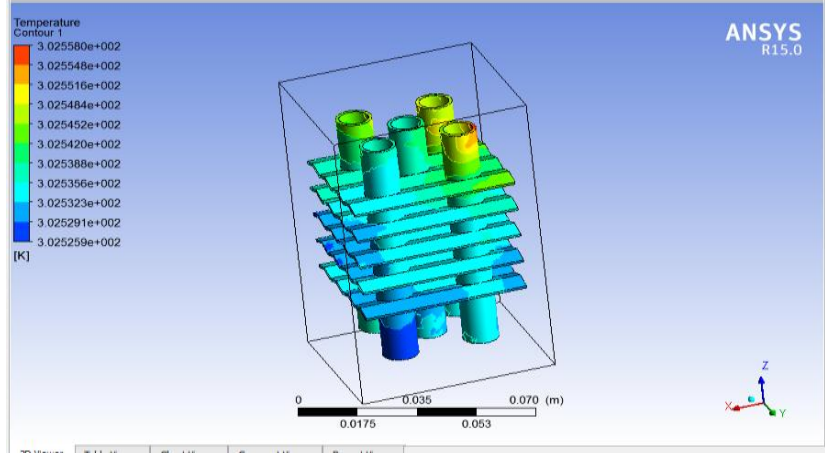

Fig.9 Temperature distribution for $17.44^{0}$ wavy angle, $70^{\circ}$ inlet water temperature and $3 \mathrm{~m} / \mathrm{s}$ air flow rate

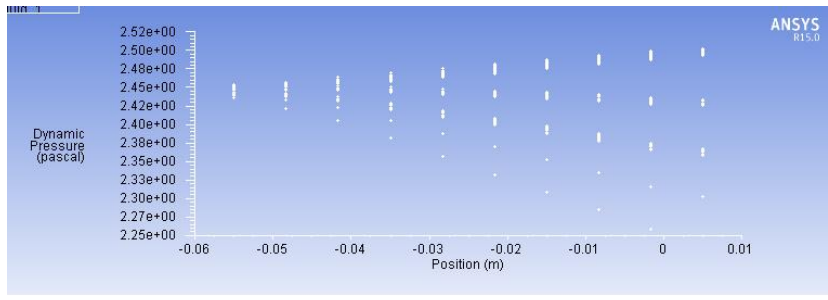

Fig.10 Pressure distribution plot for $10^{0}$ wavy angle, air flow velocity $2 \mathrm{~m} / \mathrm{s}$ and water inlet temperature $60^{\circ} \mathrm{c}$

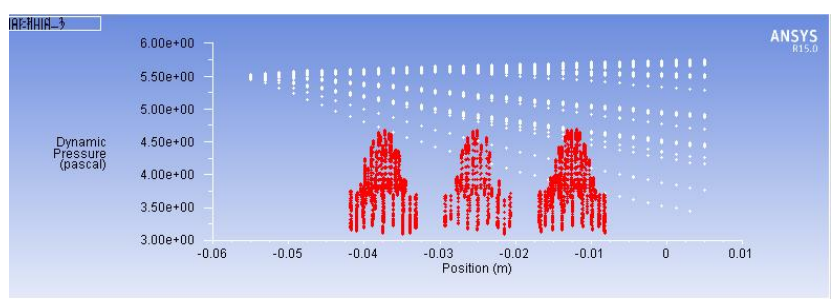

Fig.11 Pressure distribution plot for $17.44^{0}$ wavy angle, air flow velocity $3 \mathrm{~m} / \mathrm{s}$ and water inlet temperature $60^{\circ} \mathrm{c}$

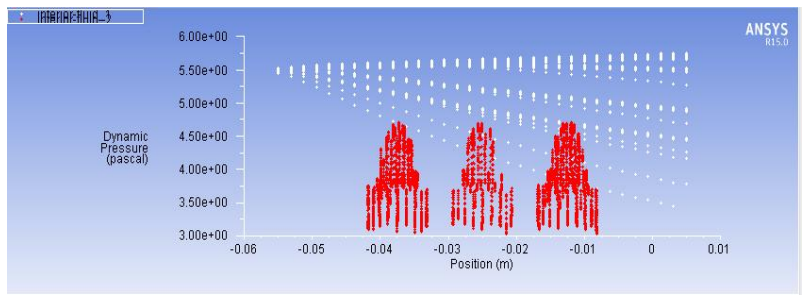

Fig.12 Pressure distribution plot for $17.44^{0}$ wavy angle, air flow velocity $3 \mathrm{~m} / \mathrm{s}$ and water inlet temperature $70^{0} \mathrm{c}$

Table 1 CFD analysis parameters and results

\begin{tabular}{|c|c|c|c|c|c|}
\hline $\begin{array}{c}\text { S. } \\
\text { No }\end{array}$ & $\begin{array}{c}\text { Wavy } \\
\text { angle } \\
\left({ }^{0}\right)\end{array}$ & $\begin{array}{c}\text { Air } \\
\text { flow } \\
\text { rate } \\
(\mathrm{m} / \mathrm{s})\end{array}$ & $\begin{array}{c}\text { Water } \\
\text { inlet } \\
\text { temp. } \\
\left({ }^{0} \mathrm{c}\right)\end{array}$ & $\begin{array}{c}\text { Max. } \\
\text { pressure } \\
\text { loss } \\
(\mathrm{pas})\end{array}$ & $\begin{array}{c}\text { Max. } \\
\text { Heat } \\
\text { flux } \\
\left(\mathrm{w} / \mathrm{m}^{2}\right)\end{array}$ \\
\hline 1 & 0 & 2 & 60 & 0.1 & 415.83 \\
\hline 2 & 10 & 2 & 60 & 0.23 & 5430 \\
\hline 3 & 17.44 & 2 & 60 & 0.75 & 9422 \\
\hline 4 & 17.44 & 3 & 60 & 1.75 & 11634 \\
\hline 5 & 17.44 & 3 & 70 & 1.85 & 12227 \\
\hline
\end{tabular}

Result shows that as the wavy angle increases Maximum heat flux goes on increasing with loss in pressure.

\section{Conclusions}

1) The present research study is related to performance enhancement of fin and tube heat exchanger, by increasing the surface area density of the heat exchanger and also improves the convection heat transfer coefficient.

2) Wavy fins are particularly attractive for their simplicity of manufacture and potential for enhanced thermal -hydraulic performance.

3) The air side thermal hydraulic performance of wavy fin and tube heat exchanger depends on geometry of wavy fin such as wavy angle , fin pitch, flow length ratio etc.

4) The CFD analysis results shows that as the fin angle increases heat flux also increases. We get maximum heat flux for the wavy angle 17.440 in the comparison that is $12227 \mathrm{w} / \mathrm{m} 2$

5) We should kept eyes on pressure loss, as wavy angle increases pressure loss also increases so it should be maintain as low as possible. For wavy angle 17.440 we get maximum pressure loss of 1.80 Pascal

\section{References}

C.C. Wang, W.L. Fu, C.T. Chang,(1997) ,Heat transfer and friction characteristics of typical wavy fin and tube heat exchangers, Exp. Thermal Fluid Science, 14,174-186.

C.C. -Wang, Y.T. Lin, C.J. Lee, Y.J. Chang,(1999), Investigation of wavy fin and tube heat exchangers: a contribution to databank, Exp. Heat Transfer , $12,73-89$.

S. Wongwises, Y. Chokeman,(2005), Effect of fin pitch and number of tube rows on the air side performance of herringbone wavy fin and tube heat exchangers, Energy Convers. Manage. , 46 ,2216-2231.

A.M. Jacobi, Y. Park, D. Tafti, X. Zhang, An assessment of the state of the art, and potential design improvement, for flat-tube heat exchangers in air conditioning and refrigeration applicationsPhase I, ARTI-21 CR/20020-01.

J.Y. Jang, L.K. Chen, (1997) , Numerical analysis of heat transfer and fluid flow in a three-dimensional wavy-fin and tube heat exchanger, Int. J. Heat Mass Transfer, 40 ,3981-3990.

R.M. Manglik, J.H. Zhang, A. Muley, (2005) , Low Reynolds number forced convection in three-dimensional wavy-platefin compact channels: fin density effects, Int. J. Heat Mass Transfer , 48,1439-1449.

T.V. Jones and C.M.B. Russell, (1980) Efficiency of rectangular fins, in: ASME/AICHE National Heat Transfer Conference, Orlando, Florida, pp. 27-30.

F.E.M. Saboya, E.M. Sparrow, (1974), Local and average heat transfer coefficients for one-row plate fin and tube heat exchanger configurations, ASME J. Heat Transfer , 96, 265-272.

E.C. Rosman, P. Carajilescov, F.E.M. Saboya, (1984), Performance of one- and two-row tube and plate fin heat exchangers, ASME J. Heat Transfer,627-632.

H. Ay, J.Y. Jang, J.N. Yeh, (2002), Local heat transfer measurements of plate finned-tube heat exchangers by infrared thermography, Int. J. Heat Mass Transfer, 45 ,40694087.

Mao-Yu Went and Ching-Yen Ho., (2009) Heat transfer enhancement in fin-and-tube heat exchanger with improved fin design, Applied Thermal Engineering, 29, 1050-1057. 